\title{
Strain Rate Effect on the Compressive Behaviour of Reinforced Cork Agglom- erates
}

\author{
Louise Le Barbenchon ${ }^{1, *}$, Jérémie Girardot ${ }^{1}$, Jean-Benoît Kopp ${ }^{1}$, and Philippe $\operatorname{Viot}^{1}$ \\ ${ }^{1}$ Arts et Métiers ParisTech, CNRS, I2M Bordeaux, Esplanade des Arts et Métiers, F-33405 Talence Cedex, France
}

\begin{abstract}
The demand for bio-sourced materials is currently increasing. Cork material because of its unique properties (fire resistant, energy absorbing, ...) is then an excellent candidate for a large set of applications. In order to widen its possible uses, cork agglomerates with reinforcements at a 0.48 density were studied to compare their mechanical performances with classical cork agglomerates.

This paper investigates the effect of these foreign reinforcements on the properties of agglomerated cork under a compressive loading. The material behavior has been determined as a function of the average strain rate and the direction of solicitation. The microstructure was first observed through optical and scanning electronic microscopy, spotting charges between each cork bead. The characterisation of cork at different strain rates was then carried out. An electromechanical testing machine was used to apply an uniaxial compression at quasi-static strain rates.

Reinforced agglomerated cork was found to be anisotropic and strain-rate dependant. Its micro-structure reveals at complex composite material influencing strongly mechanical properties. Both Young's modulus and absorbed energy density at 0.6 strain increase with the cross-head speed displacement. From $12.7 \mathrm{MPa}$ and $0.77 \mathrm{~J} \cdot \mathrm{mm}^{-3}$ when compressed at $0.05 \mathrm{~mm} \cdot \mathrm{min}^{-1}$ to $19.9 \mathrm{MPa}$ and $1.44 \mathrm{~J} \cdot \mathrm{mm}^{-3}$ at $500 \mathrm{~mm} \cdot \mathrm{min}^{-1}$ in the Off-plane direction.
\end{abstract}

\section{Introduction}

Cork is a natural material coming from the bark of the oak tree Quercus Suberus L. growing in sub-desertic areas. Europe produces $80 \%$ of the world's cork and almost three quarter of them come from Portugal [1]. It is formed by prismatic cells disposed in successive layers (Fig. 1) exhibiting a relatively homogeneous honeycomb structure. Suberin, a polymeric substance, is the major component of cork cell wall. The others are lignin, cellulose and hemicelluloses [2]. It is a very unique material due to its low density - around 0.17 -, great elasticity, chemical stability, its no permeability to liquid and gases and its resistance to fire [3]. Cork is used since decades, first by the Romans in sandals or stoppers for amphorae. Its most popular application - stoppers for glass bottles - was perfected in the $18^{\text {th }}$ century in a Benedictine Abbey at Hautvillers, France [3]. Cork by-products are today mainly developed for their thermal insulation and acoustic properties [4]. As cork is a cellular material, its absorbing properties for dynamic loadings are now being considered for impact-absorbing applications as core material in sandwich structures [5]. Ranging from the container for the transport of sensible pieces to sports items and including lightweight aeronautic components, a wide range of applications is foreseen $[1,6]$.

Previous works studied the fundamental aspects of the static mechanical behaviour of natural and agglomerated cork under simple loadings [7-9]. Mechanical proper-

\footnotetext{
*e-mail: louise.le barbenchon@ensam.eu
}

ties [3, 7, 9-12], effect of particle size [13], temperature dependency [14, 15], plasticiser effect of humidity [16] were reviewed. By comparing several agglomerates with quasi-static and impact tests, agglomerated cork products demonstrated very diverse material properties depending on the grain size, binder quantity and the processing method, making it a tailored material [17, 18]. Natural cork and cork agglomerates were also compressed at $600 s^{-1}$ [19]. The strain rate dependency of cork products was hence highlighted. The effect of the sample thickness on the absorbed energy was also investigated [20]. A recent study [21] assessed the heterogeneous deformation behaviour of cork agglomerates under a dynamic compression with Digital Image Correlation.

On the other hand the possibility to add something to the binding agent and cork grains was almost not explored. Only one publication skims over this problematic [22] for black cork (cork agglomerated by its own natural resin, suberin). They found a high content of carbonised particles of black cork to decrease the mechanical properties of an agglomeration product. Yet the influence of these particles on damage mechanisms is still not explicit. As an optimization of this material would allow to strengthen its present applications and to open new ones, it is then interesting to investigate the effect of reinforcements at quasistatic and dynamic loading.

The aim of this work is to study the mechanical behaviour of a material newly developed. It is a composite material made from a natural cellular material - the cork granules - bonded with a thermoset polymeric matrix and 


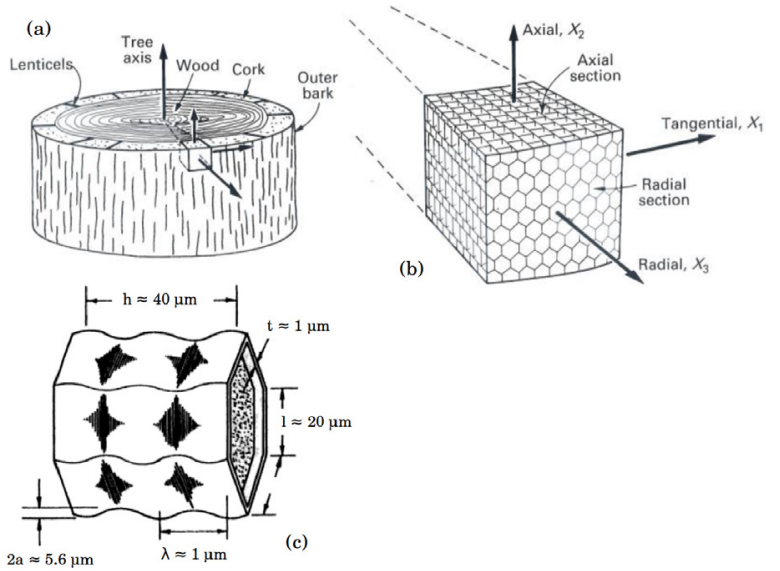

Fig. 1. a) Oak trunk with the axis system of the tree. b) Cells disposition in a cork section. c) A corrugated cork cell, showing dimensions (schemes from [23]).

reinforced by charges. The strain rate dependency and the direction of solicitation of agglomerated cork products during a quasi-static compressive loading are studied and described.

\section{Material and methods}

\subsection{Materials}

Reinforced cork agglomerates produced by the company Lieges HPK were studied. To obtain agglomerated cork, small beads $(\varnothing=0.5 / 1 \mathrm{~mm})$ were mixed together with a bio-sourced thermoset resin reinforced with short fibres $(\varnothing=7 \pm 2 \mu \mathrm{m}$ and $l=300 \mu \mathrm{m}$ ). It was then uniaxially compressed into a $1000 \times 500 \times 150 \mathrm{~mm}^{3}$ block at a 0.48 density. This compression caused a preferential orientation that will be further investigate in the article. Fig. 2 shows the two directions induced: directions in the (Oxy) plane will be called in-plane directions and $(\mathrm{Oz})$ direction will be called off-plane direction. Giving the size of granulates, this material belongs to the micro-agglomerate category. The crossing was made in an autoclave at $130{ }^{\circ} \mathrm{C}$ during 12 hours. Slab were then machined from the block.

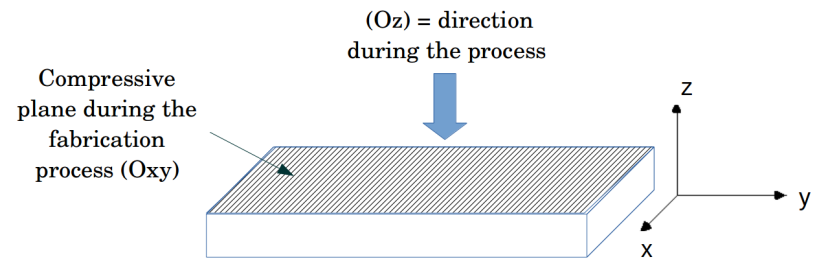

Fig. 2. Orientations resulting from the process.

\subsection{Microscopy}

Cork was first studied with an optical microscope Keyence. With the ImageJ free-software, picture analysis was operated by simplifying granulates by ellipses
(Fig. 3). Geometrical parameters of those ellipses were then used to calculate the aspect ratio AR and the granulates orientation $\alpha$. Aspect Ratio is a shape factor obtained by dividing the minor axis length by the major one $\left(A R=\frac{b}{a}\right)$. The more it is close to 1 and the more the particle tends to be circular.

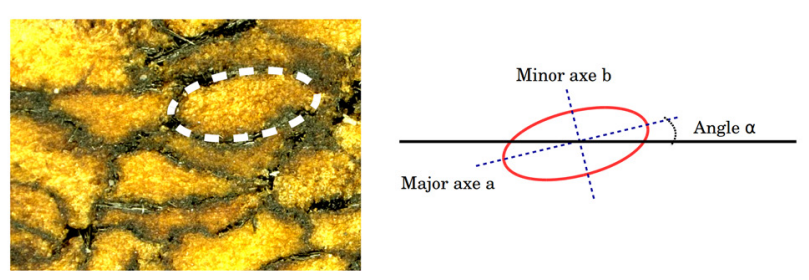

Fig. 3. Geometrical approximation for a cork granulate and ellipse parameters.

In order to observe the structure of cells, cork was observed with a SEM (Jeol JSM-7200F). Cubes were cut with a razor blade replaced for each cut in order to damage as less as possible the cell walls [16]. Each cube was cut over-size and then trimmed to the final size (roughly $5 \mathrm{~mm}$ sides) by taking thin slivers from each face to decrease cell distortion. Samples were then lightly coated with conductive gold.

\subsection{Quasi static compression}

$20 \times 20 \times 20 \mathrm{~mm}^{3}$ samples were cut from large slabs of agglomerated cork. An electromechanical traction/compression machine (Zwick Roell 250 from Allround-Line) with a load cell capacity of $250 \mathrm{kN}$ was used. The loading speed was set at $0.05,5,500 \mathrm{~mm} \cdot \mathrm{min}^{-1}$ corresponding to average strain rates of $4.2 \times 10^{-5}, 4.2 \times$ $10^{-3}$ and $4.2 \times 10^{-1} \mathrm{~s}^{-1}$. Mechanical behaviour of the two main directions was investigated.

From the force/displacement data, stress/strain curves were deducted by calculating nominal stress $\left(\sigma=\frac{F}{S_{0}}\right)$ and nominal strain $\left(\epsilon=\frac{l_{0}-l}{l}\right)$. Poisson's ratio of cork being near 0 , the section did not change during the compression test.

To obtain the Young's modulus, the curve was fitted with a seven degree polynomial. The inflection point of the elastic part of the curve was found with its second derivative. A one degree polynomial was then calculated between $\epsilon=0.01$ and this inflection point. Its slope corresponds to Young's modulus given in this article. Absorbed energy which corresponds to the sum of dissipated and elastic energies was another material parameter. It was obtained by integrating along the displacement using the composite trapezoidal rule. To be able to compare it with literature data, absorbed energy density at $60 \%$ compressive strain was calculated by integrating until $\epsilon=0.6$ and by dividing the energy found by the sample volume. 


\section{Results and discussion}

\subsection{Structure of agglomerated cork}

Naked eye observations suffice to spot differences between in-plane and off-plane directions (Fig. 4). In the off-plane direction granules (Fig. 4a) keep the aspect they had before the process. Beads in the Fig. $4 \mathrm{~b}$ display an apparent elongation in the (Oy) direction. Observations made in the $(\mathrm{Ox})$ or $(\mathrm{Oy})$ directions were similar. Consequently the plane (Oxy) appears to be isotropic.

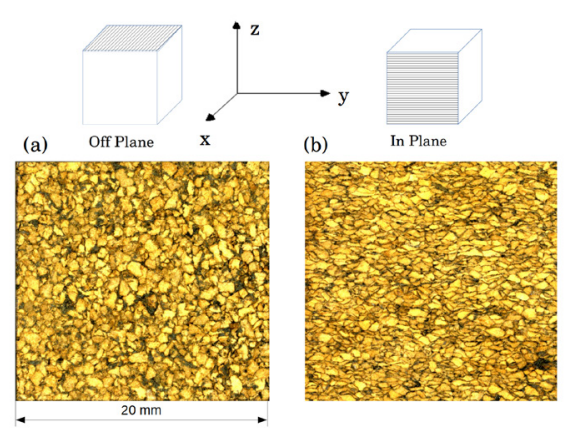

Fig. 4. Granule shape depending on the observation direction. (a) Off-plane direction, (b) In-plane direction.

Picture analysis allowed to convert beads into ellipses. It confirmed In-plane granules have mostly their major axis oriented at $0^{\circ}$ while off-plane ones are randomly facing (Fig. 5). Dimensions considerations show granules observed in the Off-plane direction tend to have an aspect ratio mostly between 1 and 3 whereas the granules observed in the In-plane direction have it between 2 and 6 (Fig. 5). Beads tend then to be rounder in the (Oxy) plane. This observation can easily be linked to the process explained in the previous section.

The microstructure of agglomerated cork demonstrates a random orientation of granulates in Fig. 6. Each bead is characterized by cells grown in one direction (specified in Fig. 1). The SEM picture shows some already compressed cells. This compression could be due to the process or to the cutting step. To rule out this last hypothesis, many cares were taken to avoid to damage cells. Yet it was not possible to obtain undamaged cells.

Short fibers are present at the interface of the beads with the resin (Fig. 7) making a $\sim 40 \mu \mathrm{m}$ thick layer. They tend to line up with the granule surface. During the mixing, beads appear to be coated with the binding agent and reinforcements most likely stick to the resin.

\subsection{Compression behaviour}

Cork compressive behaviour is typical of foam-like materials [23]. Globally no discrepancy was observed between samples compressed at the same solicitation speed. Fig. 8 shows the compressive mechanical behaviour of reinforced cork agglomerate in both directions. First for small strains (around $5 \%$ ), cork has an elastic behaviour, mainly due to cell walls and edges bending. A $1.5 \mathrm{MPa}$
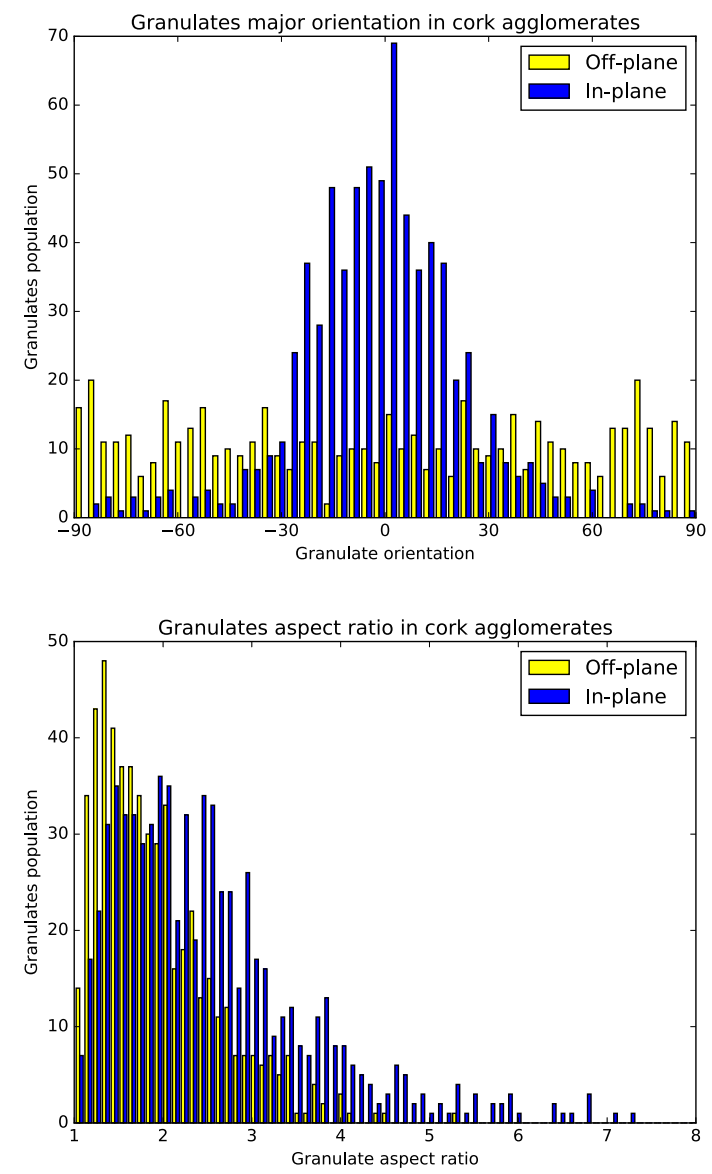

Fig. 5. Results of picture analysis. Histograms of the granulates orientation and of their aspect ratio.

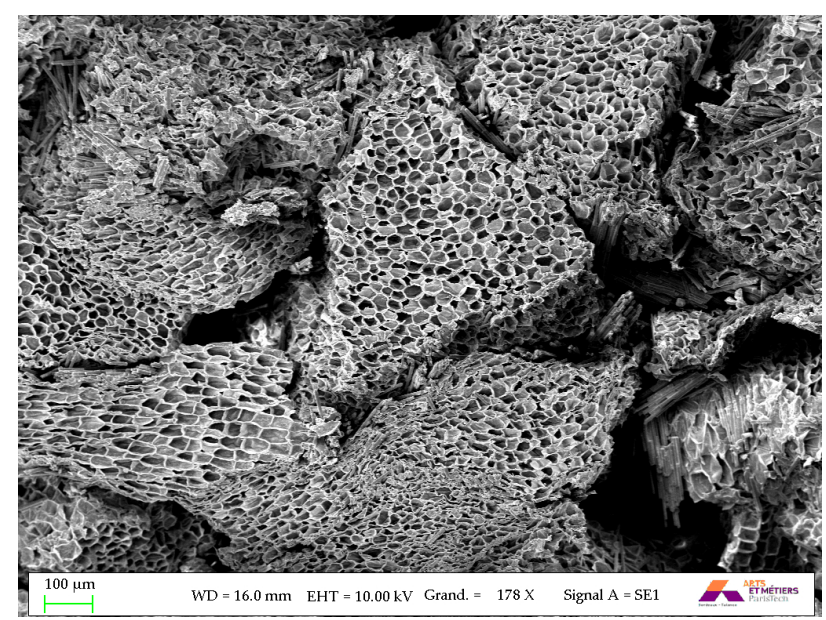

Fig. 6. Random cells orientation in cork agglomerates.

plateau follows where stress does not vary much until a 0.6 strain. During this phase, cells become more and more distorted. After that cell walls progressively collapse completely causing stress to increase strongly until approximately $25 \mathrm{MPa}$. This last stage is called the densification. 


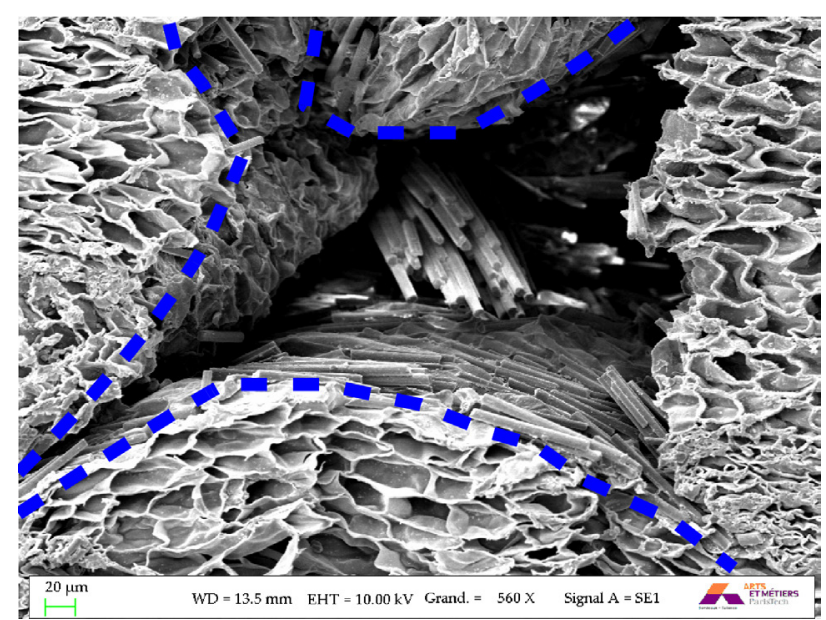

Fig. 7. Reinforcements placement between beads in reinforced cork agglomerates. Granulates are highlighted with dotted lines.

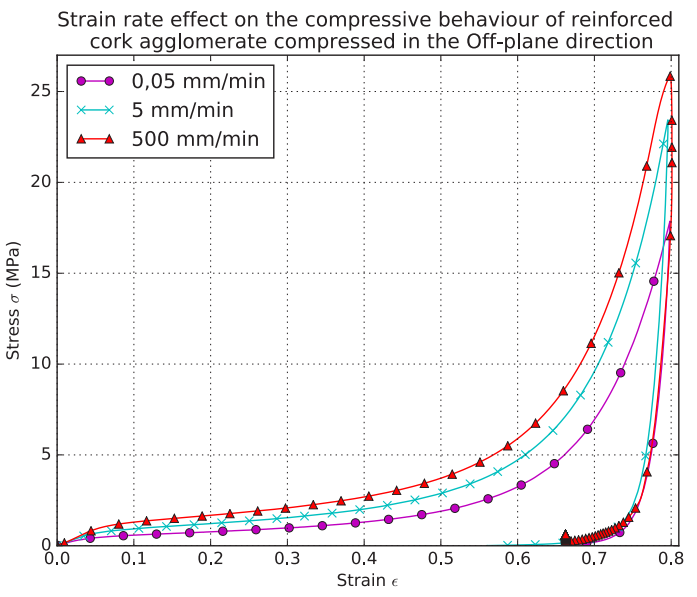

Strain rate effect on the compressive behaviour of reinforced

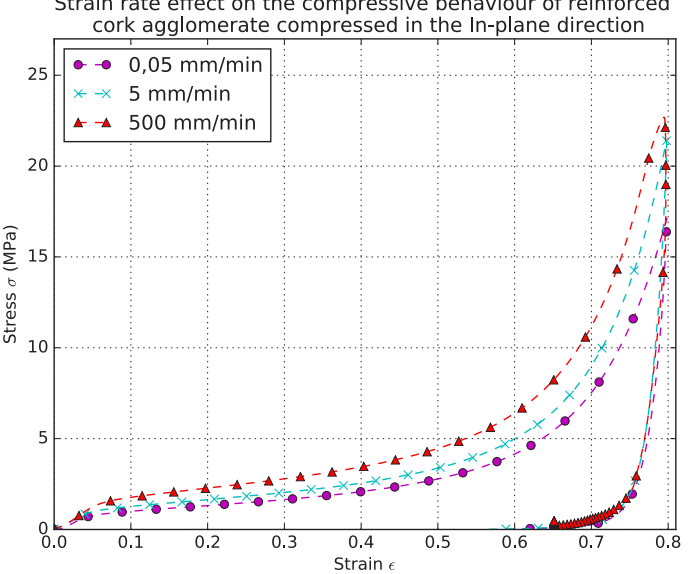

Fig. 8. General aspect of a compressive curve for agglomerated cork in the Off-plane and In-plane directions.

\subsubsection{Anisotropy of agglomerated cork}

Because of the process, the nearly isotropic behaviour of cork agglomerates mentioned in several papers [17, 18, 24, 25] was questioned. In-plane direction proves to be stiffer (Fig. 9) which can be correlated with the geometrical aspects explained earlier in the subsection Structure of agglomerated cork. Off-plane granulates are rounder and thus easier to deform explaining the fact this direction is less rigid.

Concerning the absorbed energy, In-plane compressed samples seem to absorb more energy until $\epsilon=0.6$ (Fig. 10). Around $\epsilon=0.8$, Off-plane samples reach higher stress for comparable strains (Fig. 8) leading absorbed energy at $80 \%$ compressive strain to be similar between both directions.

As the structure first hinted it, compressive tests demonstrate an anisotropic behaviour for cork agglomerates. The reason of such orientation is in all likelihood the uniaxial compression experienced by the material during the process. Although such process seems to be accurate for agglomerate cork, it was never reported before. It could come from the high density of the material studied here. To reach it, higher compression was needed.

\subsubsection{Effect of strain rate}

Young's modulus increases with the displacement speed in both directions (Fig. 9). Dispersed energy seems also to increase - almost linearly - with the displacement speed (Fig. 10).

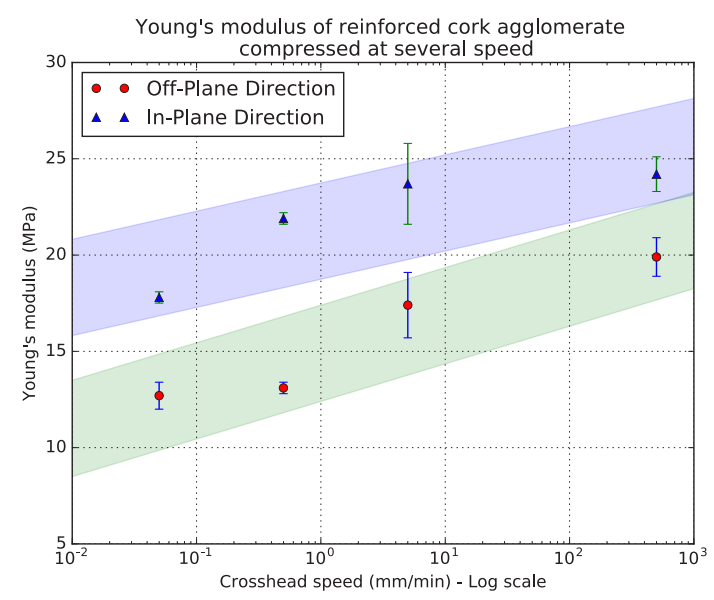

Fig. 9. Effect of the cross-head speed on the compressive Young's Modulus of reinforced cork agglomerate at room temperature and hygrometry (around $20^{\circ} \mathrm{C}$ and $\mathrm{RH} 50 \%$ ).

Hence reinforced cork agglomerate demonstrates a time-dependency at static loadings. The viscoelastic behaviour of cork had already be noticed [16, 17, 19, 21, 26]. Cork is made of several polymeric components as suberin, lignin, hemi-cellulose and cellulose and the composite contains also a polymeric resin. They demonstrate themselves viscoelastic behaviour [2, 27] though timedependency was not always detected in a given speed regime $[21,25]$.

\subsubsection{Effect of reinforcements}

A comparison with literature data was made to position the material studied in this article. Yet it has to be treated 


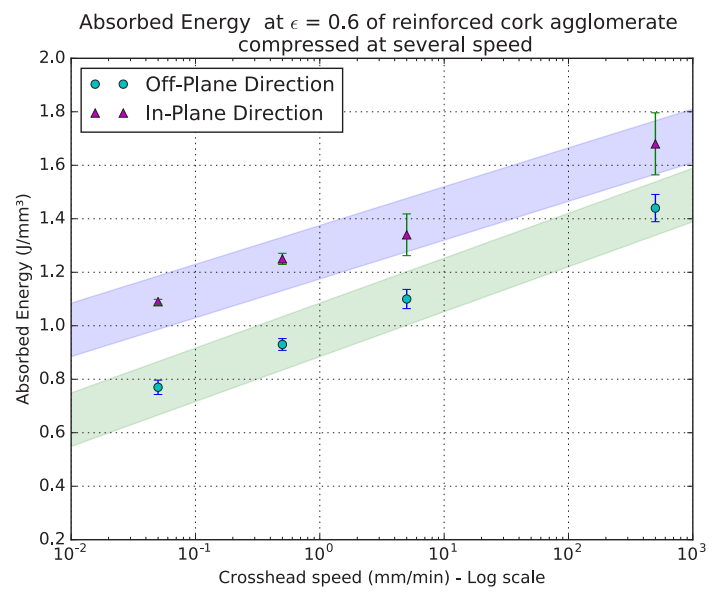

Fig. 10. Effect of the cross-head speed on the dispersed energy during the compression of reinforced cork agglomerate at room temperature and hygrometry (around $20^{\circ} \mathrm{C}$ and $\mathrm{RH} 50 \%$ ).

cautiously. Indeed as explained before, many parameters impact the mechanical properties. In Tab. 3.2.3 was summed up properties from several papers about agglomerated cork, natural cork and a polymeric foam named Rohacell. This last foam is a closed cell rigid PMI (polymethacrylimide) foam. It is commonly used as core material in aerospace products. Density, binding agent, speed solicitation, Young's modulus and absorbed energy at $\epsilon=$ 0.6 were gathered if available in the literature.

Static Young's modulus appears to be higher for natural cork than for the composite studied here (Tab. 3.2.3). It had been already noticed by [19]. Otherwise it is higher than for other cork-based products (at similar solicitation speed) and comparable with Rohacell's rigidity.

Reinforced cork agglomerates display higher absorbed energy density than literature data (Tab. 3.2.3). Young's modulus values and plateau stress are also higher (around 1.5 MPa Fig. 8) than for other agglomerates (around $0.5 \mathrm{MPA}[17,18]$ ) or for the polymeric foam (around $1 \mathrm{MPa}[28])$.

Most cork-based products are bonded with a polyurethane (PU) resin. The chemical structure of the resin influences the rigidity of cork products [18]. According to [18], if the cross-linked structure is denser, the implied lower molecular mobility of chains will lead to higher elastic modulus values and lower stretching. The densification stage will also appear sooner with stiffer resin. Therefore the binding agent could explain why the material investigated here is stiffer. In this case little is known about the binder used here. Any conclusion based on it would be uncertain.

The composite studied in this article is much denser than the one studied by [17]. Yet in this article, stored energy density seems to have somehow a proportional relationship with material density. Then the stored energy density shown by the reinforced cork agglomerate is higher than the one expected at this density. Rohacell has also a much smaller density partially explained by its cell size. The characteristic cell-wall size and cell-wall thickness are $l=0.3 \mathrm{~mm}$ and $t=12 \mu \mathrm{m}$ [28]. Cork cell parameters lie around $l=40 \mu m$ and $t=1 \mu m$ [3].

Finally - density and resin being put aside - short fibres could provide a stiffener effect. And yet the densification stage doesn't seems to start later comparing to other cork agglomerates. Indeed for natural cork it begins around a 0.65 strain [3]. On the other hand PU-bonded agglomerates densify around 0.5 [18] or 0.65 [17]. Reinforcements could then be a good way to increase the stored energy and still having a moderate plateau for high strain.

The compressive mechanical behaviour of reinforced cork agglomerate is comparable to the Rohacell behaviour. However density of this agglomerated cork is ten times higher (Tab. 3.2.3). As a potential core material, it could be a drawback. Yet the interesting recovery capacity of cork could counterbalances it. That is why cork agglomerates appear to be a good choice for structural integrity purposes as already mentioned in [29].

\section{Conclusion and perspectives}

This work tried to investigate the compressive mechanical behaviour of an innovative material made of a natural cellular material - cork -, a thermoset polymeric binder and short fibres. Micro-structure analysis was run in order to better understand the macro-structure behaviour. Quasistatic compressive tests were performed at several solicitation speeds in two different directions.

SEM pictures highlighted an intricate and heterogeneous composite material. Reinforcements and resin are present between each granulate constituting a $40 \mu \mathrm{m}$ thick layer. Short fibers seem to align with the granulate surface.

The reported results of compression and microscopy revealed the anisotropy of agglomerated cork caused by uniaxial compression during the process. In literature, such materials are always reported as quasi-isotropic. However high density agglomerates seems to enhance the gap between directions and mechanical behaviour.

The composite appeared to be viscoelastic. Young's modulus and absorbed energy density increase with the strain rate applied. From $12.7 \mathrm{MPa}$ and $0.77 \mathrm{~J} \cdot \mathrm{mm}^{-3}$ when compressed at $0.05 \mathrm{~mm} \cdot \mathrm{min}^{-1}$ to $19.9 \mathrm{MPa}$ and $1.44 \mathrm{~J} \cdot \mathrm{mm}^{-3}$ at $500 \mathrm{~mm} \cdot \mathrm{min}^{-1}$ in the Off-plane direction and from $17.8 \mathrm{MPa}$ and $1.09 \mathrm{~J} \cdot \mathrm{mm}^{-3}$ at $0.05 \mathrm{~mm} \cdot \mathrm{min}^{-1}$ to $24.2 \mathrm{MPa}$ and $1.68 \mathrm{~J} \cdot \mathrm{mm}^{-3}$ at $500 \mathrm{~mm} \cdot \mathrm{min}^{-1}$ in the Off-plane direction.

By adding short fibres to the agglomerated cork, the material keeps good absorption properties with a moderate stress plateau (around 1.5 MPa) for high strains. This feature being the main one foreseen for cork, it can be concluded that reinforced cork agglomerates could be suitable for some energy absorption applications.

A deeper study of its strain and damage mechanisms would allow to better understand not only this material but also to increase the knowledge on cork agglomerates behaviour under extreme solicitations like strain rate or temperature. A comparison with the same material without reinforcements would be later conducted to assess the accurate effect of this charges on the mechanical behaviour 
Table 1. Literature data about cork products mechanical properties and one closed-cells foam material (Rohacell). AC = agglomerated cork, MAC = micro agglomerated cork (particle size between 0.5 and $1 \mathrm{~mm}$ ), PU = polyurethane.

\begin{tabular}{|l|l|l|l|l|l|}
\hline Article & Material & Density & $\begin{array}{l}\text { Solicitation } \\
\text { speed } \\
\left(\mathrm{mm} \cdot \mathrm{min}^{-1}\right)\end{array}$ & $\begin{array}{l}\text { Young's } \\
\text { modulus } \\
(\mathrm{MPa})\end{array}$ & $\begin{array}{l}\text { Absorbed energy } \\
\text { density }\left(\mathrm{J} \cdot \mathrm{mm}^{-3}\right) \\
\text { at } \epsilon=60 \%\end{array}$ \\
\hline This paper & MAC & 0.48 & 5 & 18 & 1.12 \\
(Jardin et al., 2015) & MAC PU & 0.199 & 5 & 4.5 & 0.8712 \\
(Sasso et al., 2018) & MAC PU & 0.2 & 3 & 4 & - \\
(Julien Mairesse, 2009) & AC & 0.27 & 9 & 6.6 & - \\
(Santos et al., 2017) & MAC PU & 0.2 & 9 & - & 0.4 \\
(Gibson et al., 1981) & Natural Cork & 0.17 & - & 20 (radial) & - \\
(Q.M Li et al., 2000) & Rohacell 51 WF & 0.052 & 1 & 22 & $\approx 0.5$ \\
\hline
\end{tabular}

of cork agglomerates. Higher strain rates will also be reached thanks to Hopkinson bars and time-dependency at dynamic loadings will then be studied.

The authors would like to thank Lieges HPK for providing reinforced cork agglomerates. Jérémie Béga is thanksfully acknowledged for helping us with SEM pictures.

\section{References}

1. L. Gil, Materials 8, 625 (2015)

2. S.P. Silva, M.A. Sabino, E.M. Fernandes, V.M. Correlo, L.F. Boesel, R.L. Reis, International Materials Reviews 50, 345 (2005)

3. L.J. Gibson, K.E. Easterling, M.F. Ashby, Proceedings of the Royal Society A: Mathematical, Physical and Engineering Sciences 377, 99 (1981)

4. L. Gil, Materials 2, 776 (2009)

5. F.C. Potes, J.M. Silva, P.V. Gamboa, Composite Structures 136, 430 (2016)

6. M.M. Mateus, J.M. Bordado, R.G. dos Santos, Ciência \& Tecnologia dos Materiais 29, 65 (2017)

7. M.E. Rosa, J. Osorio, V. Gree, Materials Science Forum vol. 455-4, pp. 235 (2004)

8. O. Anjos, C. Rodrigues, J. Morais, H. Pereira, Materials and Design 53, 1089 (2014)

9. M.A. Fortes, M.T. Nogueira, Materials Science and Engineering vol. A122, pp. 227 (1989)

10. M.E. Rosa, M.A. Fortes, Journal of Materials Science 26, 341 (1991)

11. O.S. Anjos, H. Pereira, M.E. Rosa, Materials and Design 31, 2085 (2010)

12. O. Anjos, H. Pereira, M.E. Rosa, European Journal of Wood and Wood Products 69, 557 (2011)

13. J.C. Motte, J.Y. Delenne, C. Barron, É. Dubreucq, C. Mayer-Laigle, Industrial Crops and Products 99, 126 (2017)
14. A. Sen, J. Van Den Bulcke, N. Defoirdt, J. Van Acker, H. Pereira, Thermochimica Acta 582, 94 (2014)

15. H. Pereira, Wood Science and Technology 26, 259 (1992)

16. A. Lagorce-Tachon, T. Karbowiak, D. Champion, R.D. Gougeon, J.P. Bellat, Materials and Design 82, 148 (2015)

17. R. Jardin, F. Fernandes, A. Pereira, R. Alves de Sousa, Materials \& Design 68, 121 (2015)

18. P.T. Santos, S. Pinto, P.A. Marques, A.B. Pereira, R.J. Alves de Sousa, Composite Structures 178, 277 (2017)

19. C.P. Gameiro, J. Cirne, G. Gary, Journal of Materials Science 42, 4316 (2007)

20. S. Sanchez-Saez, S.K. García-Castillo, E. Barbero, J. Cirne, Materials \& Design (1980-2015) 65, 743 (2015)

21. M. Sasso, E. Mancini, G. Chiappini, F. Sarasini, J. Tirillò (2018)

22. M.A. Díaz-Díez, A. Díaz-Parralejo, A. MacíasGarcía, P. De la Rosa Blanco, V. Gómez-Serrano, Indian Journal of Engineering and Materials Sciences 10, 419 (2003)

23. L.J. Gibson, M.F. Ashby, Cellular Solids: Structure and Properties, cambridge edn. (Cambridge University Press, Oxford, 1997)

24. J. Mairesse, Ph.D. thesis, Université de Bordeaux (2010)

25. R.A.S. Moreira, F.J.Q. De Melo, J.F. Dias Rodrigues, Journal of Materials Science 45, 3350 (2010)

26. J.F. Mano, Journal of Materials Science 37, 257 (2002)

27. A. Lagorce-Tachon, Ph.D. thesis, Université de Bourgogne Franche-Comté (2015)

28. Q.M. Li, R.A.W. Mines, R.S. Birch, International Journal of Solids and Structures 37, 6321 (2000)

29. O. Castro, J.M. Silva, T. Devezas, A. Silva, L. Gil, Materials and Design 31, 425 (2010) 